\title{
Comparative Criminal Justice (2nd edn.)
}

\author{
Francis Pakes. Willan Publishing, Devon, UK, 2010: \\ ISBN: 978-1-84392-769-3, v-ix +212 pages, £20.99 (Paperback)
}

\author{
Michael Adorjan
}

Received: 16 August 2010 / Accepted: 18 August 2010 /

Published online: 7 September 2010

(C) The Author(s) 2010. This article is published with open access at Springerlink.com

Pakes' book Comparative Criminal Justice is ambitious. The book provides a broad, topically geared and internationally comparative introduction to criminal justice. It follows a tried-and-true yet practical progression from policing, pre-trial and trial systems, punishment, and finishing with chapters on international policing and the development of universal human rights and international courts of justice. Each chapter offers a general introduction to areas that are then elaborated with reference to differing cultural contexts. Case studies are frequently presented in boxes that help flesh out the main arteries of thought, and often help introduce further comparisons and contrasts. The book is most suitable for undergraduate students, though its insights may appeal to a broad readership, including criminal justice practitioners and those involved in policy.

The strongest feature of Comparative Criminal Justice is its inclusiveness. Pakes underscores at several points his argument that a comprehensive comparative lens must take into account both quantitative and qualitative approaches (p. 9); that "the question of meaning remains highly pertinent" (p. 30); and that no matter how global our perspective, we should be carefully attuned to the local exigencies of culture under which globalization trends in criminal justice are appropriated and attuned. This is the second edition of the book, featuring reference to current events [e.g., discussion of Obama's potential recognition of the International Criminal Court (p. 179)]. Pakes aims to go "beyond police, courts and prisons" (p. 1) by including discussion on, for example, privatized policing and security, criminal justice in the Middle East (including Sharia law), and cybercrime, including reference to the 'great firewall of China'.

The best chapter opening is for the chapter on systems of trial (p. 86). Pakes begins with an elaborated discussion on the ergonomic features and layout of courtrooms, suggesting that the spatial relationships of courtrooms, for instance the placement of defendant in relation to the judge, illustrates much about the style and operation of the court systemespecially when comparing adversarial and inquisitorial systems. Pakes sustains his references to ergonomics throughout the chapter, which serves to underscore theoretical and conceptual points. This proves to be a pedagogically effective approach.

M. Adorjan ( $\triangle)$

Department of Sociology, The University of Hong Kong, Pokfulam Road, Pokfulam, Hong Kong e-mail: madorjan@hku.hk 
A consistent theoretical thread is upheld throughout the book regarding the differences, advantages and disadvantages of adversarial and inquisitorial judicial systems. During discussions about which nations gravitate towards which system, Pakes successfully underscores why certain international criminal justice initiatives (such as international tribunals) encounter problems: they pool actors from different cultural contexts who hold differing approaches. Part of the way forward, Pakes implies, involves understanding the geo-historical roots that have shaped variegated systems worldwide, and arriving at compromises that work. Another theoretical point with resonance is his frequent referrals to levels of trust or distrust in governments and crime control authorities. Pakes argues that "the type of person society decides to put its faith in with regard to dealing with alleged wrongdoers hinges on the answer to the question of whom to trust" (p. 120). Perhaps the work of David Nelken should be more prominent here, given Nelken's advocacy of research on trust to further comparative criminology. Nevertheless, while never a central point, it becomes obvious that nations with neoliberal systems often hold higher levels of distrust, leading to particular crime control responses (penal populism is discussed in the chapter on punishment). It is equally obvious that nations with higher levels of trust in the state and crime control respond quite differently to crime. Pakes is quick, however, to offer up-to-date evidence that, for instance, the 'rosy' image of crime control in the Netherlands needs tempering in light of recent evidence challenging the region's classic reluctance to rely on imprisonment (p. 130).

Pakes is critical towards theories of globalization, arguing that there still exists an enormous gap between those with access to information technologies and the advantages of 'space-time compression' (p. 151) and those left out (and left 'local'). He notes, "against global winners we must set large groups of clearly identifiable global 'have nots"” (p. 153). For all the discussion on globalization, however, I found it surprising that no reference is made to Bauman's writings, especially on 'glocalization'. It would be worthwhile to make this connection considering Pakes' already developed analyses on local-global interconnections and limitations. As Pakes says, "we can continue to look at national or local arrangements but we must be aware of the fact that globalisation also impacts on [them]" (p. 21), adding "the differential impact of globalisation on local communities is a key area of comparative research" (p. 22). Pakes is likely well aware of areas where more theoretical muscle could be added, but chooses to refrain to make the text accessible to an undergraduate student audience. Nevertheless, student receptivity to theoretical criminology should not be underestimated.

It is interesting to consider whether an effective comparative analysis is enabled by a value neutral or critical orientation. Pakes is certainly value neutral (for the most part), especially when carefully discussing the details of Sharia law and Islamic systems of crime control (pp. 96-99). He states facts associated with gender disparities here without making further critical remarks: "In most Islamic courts evidence from a male witness counts heavier than that from a female witness and in some jurisdictions women hardly appear at all as witnesses" (p. 98). His non-judgmental analysis allows readers to consider complexities and ambiguities and ultimately make up their own minds. As he notes, such an analysis may help prevent ethnocentrism (p. 3). In some locations, however, Pakes' political and critical leanings are more evident: e.g., in his reference to Kenya as a nation that "ridicules the notion of 'free' state police" (p. 57); or in his reference to the "pervers [ity]" that in the Netherlands suspects' rights are "severely limited" due to the feeling that "the presence of a defense lawyer would hinder the development of rapport between interviewer and suspect" (p. 75). It may be, indeed, safer to critique Western criminal justice systems than Islamic systems animated more by religion than legal protocol. Pakes 
seems to be deliberately holding back his criticisms of Islamic systems, but does so likely to promote empathy and understanding. As Pakes notes at the end of this chapter, "there is no easy way of judging which [system] is better or worse. That would probably be a meaningless exercise" (p. 103). The reader will be left to decide if Pakes could (and should) be more critical here in the same manner as he is - with much greater ease - with respect to occidental regions.

Pakes asserts that despite pressure on scholars of comparative criminal justice to be experts on everything, this is impossible (p. 11); indeed a book on comparative criminal justice should not try to be everything to everyone, for too much would be lost. Nevertheless, there are areas where minor mistakes are made that may be more noticeable to readers in Southeast Asia. For instance Pakes incorrectly asserts that Hong Kong's Independent Commission Against Corruption was founded in 1994 (p. 56), when in fact (referring to the same ICAC source Pakes himself cites) it was founded in 1974. This has implications for the discussion, as Pakes refers in this section to the 1990s, not the 1970s, as a period during which Hong Kong was embroiled in "the fight against corruption," which took "centre stage" (p. 56), and discusses ICAC statistics as recent as 2009. I also feel that Pakes presents too uncritically the 'zero tolerance' success of New York City during the 1990s under mayor Giuliani (pp. 51-52). He may have at least referred to skeptics who have pointed to trends indicating declining crime rates before Giuliani took office. Overall, however, these points are minor quibbles and in no manner detract from the validity and rigorous scholarship that runs consistently throughout the text.

Readers interested in Hong Kong and China may note Pakes' attention to these areas. Hong Kong's recent inclusion in the United National International Crime Victims Survey facilitates this. Pakes' discussion of Internet censorship in China via its 'great firewall' is given balanced treatment. He refers to the initiative's real name, the Golden Shield Project, and presents a series of facts about it while reserving judgement (p. 160). While readers invested in researching these areas will not be satisfied about the attention they receive (short paragraphs embedded in larger comparative discussions), this is to be expected in a book that is careful not to place too much emphasis on any particular area. While Asian and Middle Eastern regions receive attention, the book is often more robust in its intra-regional comparisons within Europe, with frequent references to the US as well. This is obviously due to Pakes' experience researching these areas, though more sustained attention to areas outside of Western domains would help underscore insights Pakes makes in reference to neoliberalism (p. 151) and nations that do not seem to follow the same neoliberal patterns of certain Western regions.

Comparative Criminal Justice may serve its purposes best as a springboard to both classroom discussion and further research. It is evident that comparative criminology is still an emerging area, with questions and criticisms regarding methods, theories, and whether or not a more critically oriented engagement is appropriate. Pakes guards against critical approaches, perhaps due to reservations that a descent into pejorative assessments would stymie the ability to explore culturally specific meanings. The book is a success, in any event, which helps to break readers out of ostensibly myopic criminological research.

Open Access This article is distributed under the terms of the Creative Commons Attribution Noncommercial License which permits any noncommercial use, distribution, and reproduction in any medium, provided the original author(s) and source are credited. 